\title{
Melatonin: shedding light on infertility? - a review of the recent literature
}

\author{
Shavi Fernando ${ }^{1,2^{*}}$ and Luk Rombauts ${ }^{1,3}$
}

\begin{abstract}
In recent years, the negative impact of oxidative stress on fertility has become widely recognised. Several studies have demonstrated its negative effect on the number and quality of retrieved oocytes and embryos following in-vitro fertilisation (IVF). Melatonin, a pineal hormone that regulates circadian rhythms, has also been shown to exhibit unique oxygen scavenging abilities. Some studies have suggested a role for melatonin in gamete biology. Clinical studies also suggest that melatonin supplementation in IVF may lead to better pregnancy rates. Here we present a critical review and summary of the current literature and provide suggestions for future well designed clinical trials.
\end{abstract}

Keywords: Melatonin, Oxidative stress, Oxygen scavenger, Infertility, In-vitro fertilisation

\section{Introduction}

Over the last 35 years, infertility treatment has become more acceptable and with improvements in technology the pressure for improved success rates has mounted. This trend is perpetuated by a perceived ability to delay and yet successfully achieve pregnancy through assisted reproductive technologies (ART) [1]. Technological advancement and societal expectations therefore mandate continual improvement in in-vitro fertilisation (IVF) success rates, inspiring research into novel adjuvant therapies designed to improve IVF outcomes. More recently, it has been discovered that an imbalance of reactive oxygen species, or 'oxidative stress', can have a negative impact on the success of infertility treatments, and furthermore, investigators have begun addressing potential mechanisms of preventing these effects with the use of novel oxygen scavengers such as melatonin. It may be that these agents have a positive effect on pregnancy success rates following IVF treatment. We present a summary of the most recent work investigating melatonin and its affect on oxidative stress, with a focus on the reproductive system and the treatment of infertility.

\footnotetext{
* Correspondence: shavif@hotmail.com

${ }^{1}$ MIMR-PHI Institute of Medical Research, 246 Clayton Rd, Clayton 3168,

Victoria, Australia

${ }^{2}$ Monash University, Department of Obstetrics and Gynaecology, Level 5 Monash Medical Centre, 246 Clayton Rd, Clayton 3168, Victoria, Australia Full list of author information is available at the end of the article
}

\section{Melatonin}

Melatonin: synthesis and degradation

Melatonin (N-acetyl-5-methoxytryptamine) was first isolated in 1958 as a neuro-hormone mainly synthesised and secreted from the pineal gland [2]. Since its discovery, further investigation has revealed that it is also produced by several other organs. It has been found in the gastrointestinal tract [3], brain [4], eye [5], lungs [6], skin [7], kidney [8], liver [9], thyroid, thymus, pancreas [10], immune system [11] and reproductive system [12]. Melatonin is an indoleamine, which is synthesised from the essential amino acid, tryptophan [13]. Its production is dependent on ambient illumination, with release being suppressed by light. Hence, endogenous levels in plasma begin to increase between 1800 and $2000 \mathrm{hrs}$ and peak between midnight and $0500 \mathrm{hrs}$ with levels before $0900 \mathrm{hrs}$ being five times higher than those after 1100 hrs [14]. This diurnal variation can make comparative studies challenging.

In an investigation of the pharmacokinetics of exogenous orally administered melatonin, Waldhauser and associates found that the increase in serum levels after oral administration of melatonin is rapid (60-150 minutes), as is its excretion [15]. It does not accumulate in the blood, with repeat dosing simply resulting in peak levels being maintained for longer [15]. Melatonin is hepatically metabolised and renally excreted [16]. Hence, melatonin has a short half-life and both melatonin and its metabolites can be measured in serum, urine and saliva $[17,18]$. 


\section{Actions and safety of melatonin Classical actions}

Melatonin has been identified as a key factor in the regulation of circadian rhythms and the sleep-wake cycle [18]. Long exposure to artificial lighting leads to a reduction in endogenous melatonin exposure [19]. Melatonin is thus associated with sleep disturbances including insomnia, and much of the literature is focused in this area [20-22]. It also appears to regulate reproductive seasonal variation in many animal species [18,23-25]. However, despite a daily circadian rhythm being demonstrated in uterine artery blood flow [26], seasonal breeding does not apply to primates [27], raising questions as to what other roles it may serve in humans.

\section{Actions as an oxygen scavenger}

Free oxygen radicals are created when oxygen is utilised in metabolic processes. These radicals contain 'free' valence electrons, making them highly reactive, capable of causing injury to cells [28]. The term 'reactive oxygen species' (ROS), not only includes free radicals but also stable nonradical molecules which are capable of causing oxidation, such as hydrogen peroxide $\left(\mathrm{H}_{2} \mathrm{O}_{2}\right)$ [29]. While ROS are necessary for essential physiological processes, an overabundance can result in cellular damage, commonly referred to as 'oxidative stress' [30]. Anti-oxidative agents (oxygen-scavengers) are present endogenously but can also be administered exogenously. They reduce free radicals by donating electrons to stabilise them [31].

Recently, it has been discovered that melatonin has important oxygen-scavenging properties [32-34]. Compared with other oxygen scavengers, melatonin is of particular interest because it has several qualities distinguishing and rendering it superior to classical anti-oxidative agents. For example, it has anti-oxidative effects through its receptors, MT1 and MT2 [35], but also as a direct free radical scavenger [36,37]. It has binding sites within the nucleus $[13,38]$, and is amphiphilic, allowing it to cross cell membranes freely [36,39]. But one of its most unique characteristics is that, unlike classical anti-oxidants, melatonin is a suicidal terminal anti-oxidant. It does not promote oxidation under any circumstances and its metabolites are also capable of acting as anti-oxidants in a 'scavenging cascade reaction' without themselves becoming oxidative [37,40-42]. Importantly, melatonin also enhances the activity of other endogenous antioxidants including glutathione peroxidase and superoxide dismutase (Figure 1) [43-47].

These unique characteristics have made melatonin the subject of investigation into medical conditions in which oxidative stress has been implicated, including diabetes, glaucoma, irritable bowel syndrome and even in curtailing the side effects of chemo- and radiotherapy [48,49]. Melatonin has been shown to suppress tumour growth factors and angiogenesis, suggesting a possible role for melatonin in prevention of cancer growth [9,50,51]. Furthermore, melatonin has been shown to have antiinflammatory and DNA stabilising actions in the lung [6,52], skin and intestine [53-56] and can help reduce chronic pelvic pain in women with endometriosis [57].

\section{Importance of melatonin in reproduction}

In humans, the only data on cyclical melatonin changes comes from women undergoing ovarian stimulation. Levels of melatonin reach a nadir in the preovulatory phase and peak in the luteal phase (Figure 2) [58-60]. This suggests that melatonin has variable effects dependent on the menstrual phase.

It is also well known that shift-workers are more likely than daytime workers to experience circadian disruption and longer menstrual cycles, more menorrhagia and dysmenorrhoea $[61,62]$. These results are corroborated by a very large cohort study, which also found that duration of shiftwork was modestly associated with menstrual cycle irregularity [63]. A Japanese study found that melatonin levels varied significantly between night and day shift workers, while LH and FSH levels did not, suggesting that the menstrual irregularity associated with shiftwork could be explained by melatonin fluctuations [64].

These findings are in line with central effects on the hypothalamic pituitary axis, being capable of modifying the release of gonadotrophins and GnRH [65]. In fact, in very high doses, when combined with progesterone, melatonin has the ability to suppress ovulation in humans, possibly by interfering with LH release [66]. This may represent an evolutionary remnant with inhibition of ovulation during darker months designed to prevent the birth of offspring when resources are less abundant.

Interestingly, melatonin receptors have been found on granulosa cells, indicating that this may be an additional site of melatonin activity $[65,67,68]$. Indeed, when given systemically in cats, melatonin appears to accumulate preferentially in the ovaries compared with other organs [69] and higher concentrations of melatonin are found in preovulatory follicular fluid than in serum [36,70,71]. A human study by Nakamura et al. [72] found that larger preovulatory follicles had higher concentrations of follicular fluid melatonin than smaller immature follicles. This is the only study that has addressed follicular fluid differences within the same patient, and indicates that follicular fluid from mature follicles have higher antioxidant capacity than smaller follicles, implying a role for melatonin in oocyte maturation. However, it is as yet unclear whether this is a cause or consequence.

Adding further credence to the role of melatonin in reproduction, melatonin requirements appear to increase during pregnancy [73], and researchers have begun to assess its role as a potential therapy in pre-eclampsia and 
neonatal neurological morbidity $[74,75]$. Recent investigations have shown that in ovine models, intrauterine infusion of melatonin results in an increase in umbilical artery blood flow and higher fetal-placental weight ratio. Importantly, intrauterine infusion of a melatonin receptor antagonist decreased fetal aortic blood flow relative to fetal weight, suggesting that activation of melatonin receptors may be the mechanism behind the apparent increase in fetal blood flow after oral melatonin supplementation [76].
Melatonin has also been shown to reduce the neurological effects of oxidative stress-induced fetal brain injury in rats and sheep $[77,78]$. These findings support a beneficial role of melatonin in the treatment and/or prevention of placental dysfunction, which may even extend to the treatment of pre-eclampsia and neurological damage in preterm and growth restricted neonates $[4,78]$.

Because melatonin levels naturally decrease with age $[79,80]$, some investigators have found that supplementation

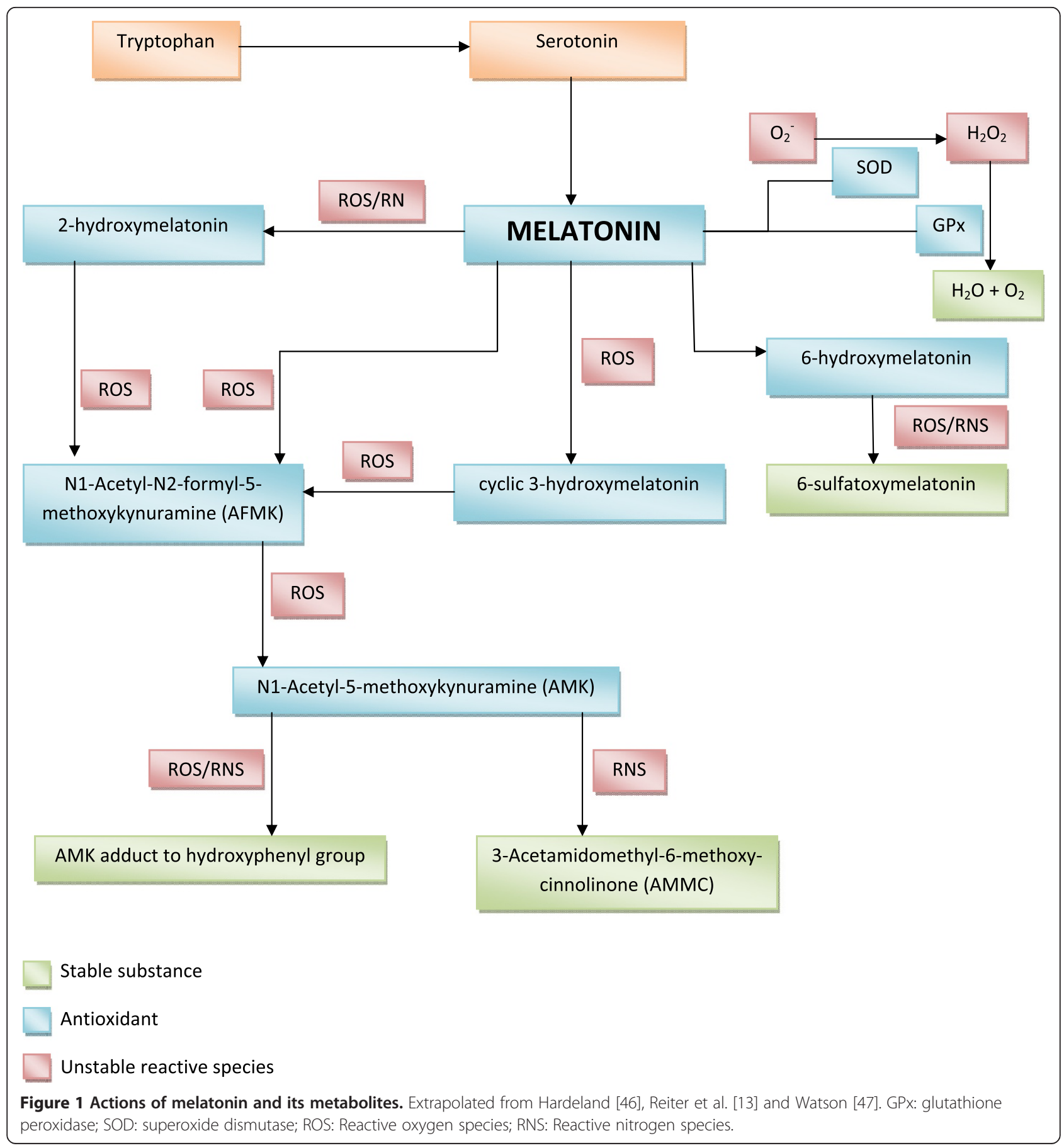


Melatonin

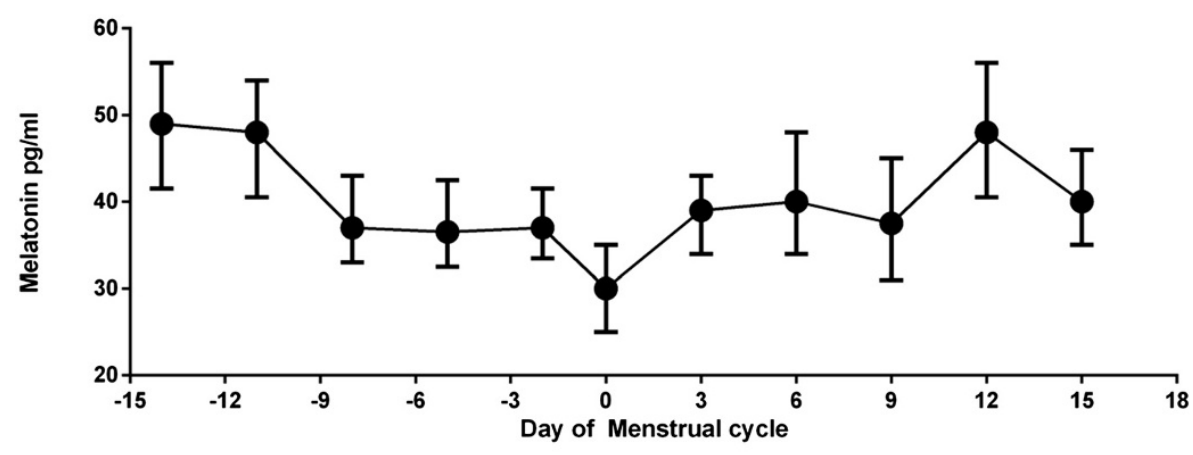

LH

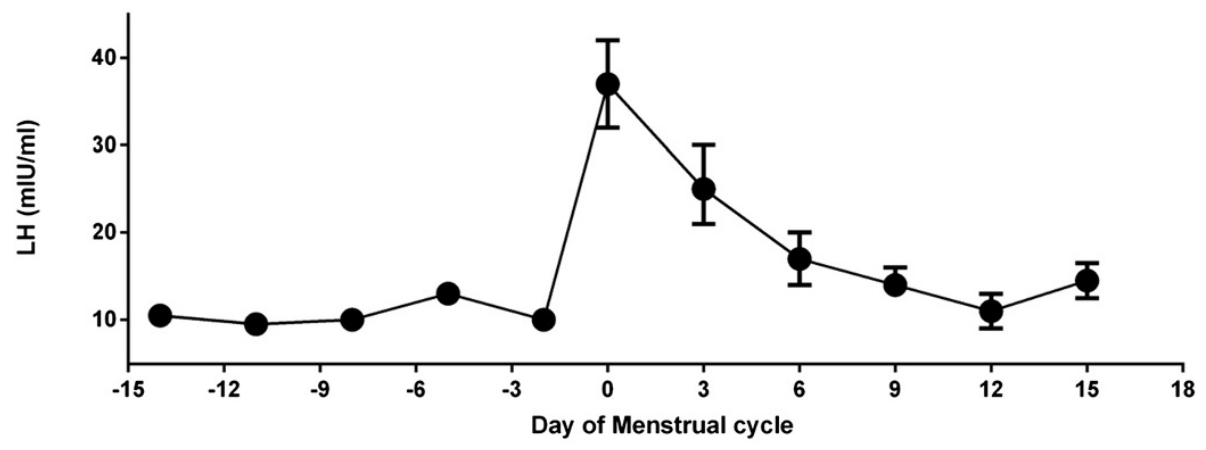

Oestradiol

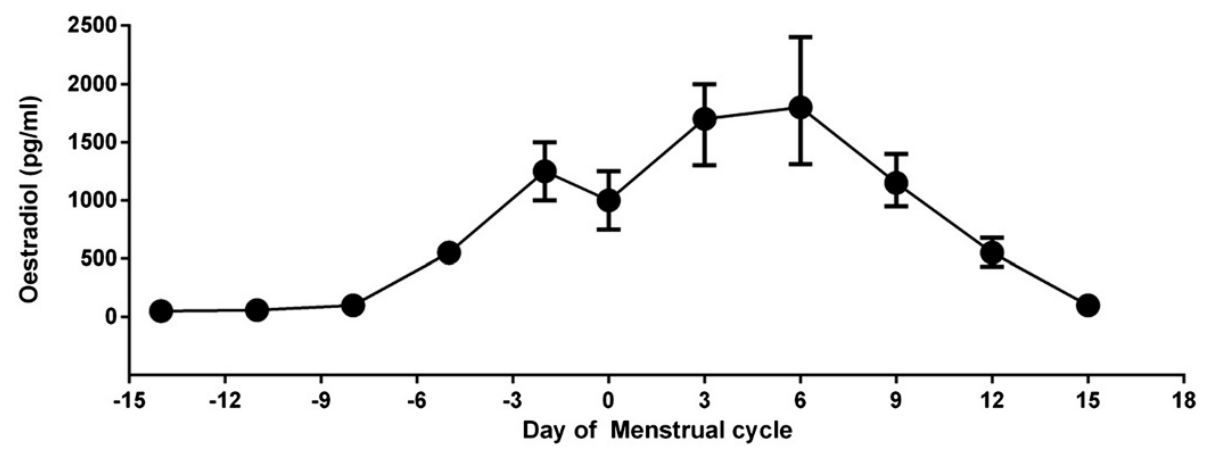

Progesterone

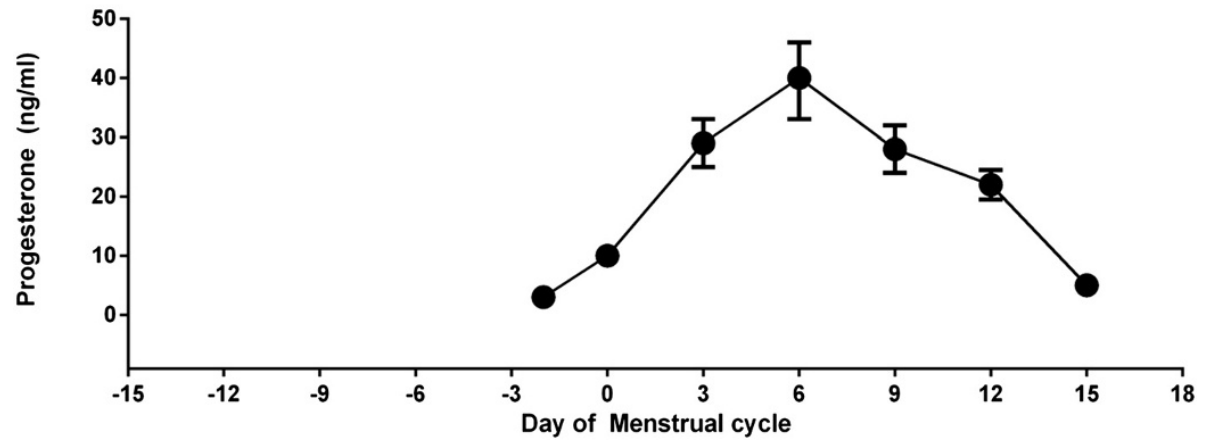

Figure 2 Relative concentrations of plasma melatonin, LH, estradiol and progesterone in hMG/hCG treated cycles. Adapted with permission from Tang et al. [59]. LH: Luteinising hormone. 
may also have a role in the climacteric [81]. Melatonin also appears to have a role in the prevention of postmenopausal bone loss, with effects being exerted via inhibition of oxidative stress, induction of osteoblastogenesis and inhibition of osteoclastogenesis [82]. These findings and evidence from a small randomised controlled trial suggests that melatonin may be useful in the treatment of perimenopausal and menopausal symptoms and sequelae $[83,84]$.

The positive implications of higher melatonin levels on the human menstrual cycle, fertility and pregnancy are therefore well documented, with varying levels of evidence $[32-34,85]$. Nevertheless, it appears clear that melatonin serves a purpose in the human reproductive system, with many of its observed effects likely to be related to its ability to dampen the effects of oxidative stress on the reproductive system.

\section{Safety}

Given the potential clinical benefits of melatonin it is equally important to assess its potential for harm, particularly when considering treatment in infertile or pregnant populations. It is reassuring that melatonin has a remarkably benign safety profile in both animal and human studies, with no teratogenic effects [86-88]. Furthermore, melatonin does not have significant sedative effects and is not associated with hepato-nephrotoxicity [89] even at supraphysiological doses (5 - $20 \mathrm{mg} /$ day) for prolonged periods of administration (up to 12 weeks) in both adults and children [66,90-92]. While non-toxic, it has been suggested that melatonin can adversely affect autoimmune conditions, particularly rheumatoid arthritis [93], through its immuno-stimulatory actions. There have also been two case-reports of melatonin being associated with autoimmune hepatitis $[94,95]$, and a suggestion that it may be implicated in multiple sclerosis through T-cell activation [96]. Though these effects are associative and follow biological plausibility, causality has not yet been proven [97]. Despite this, it is recommended to avoid the use of melatonin in those with autoimmune conditions.

\section{Infertility treatment}

\section{The importance of oxidative stress in assisted}

\section{reproductive technology (ART)}

The relevance of oxidative stress in ART has gained increasing attention in recent literature, in particular with regards to IVF. IVF can result in exposure of oocytes and embryos to high levels of superoxide free radicals, which begins prior to oocyte retrieval [98]. Ovarian stimulation protocols are associated with significant changes to the in-vivo follicular environment, altering endogenous levels of oxygen scavengers [99]. Furthermore, in-vitro, these oocytes are no longer protected by antioxidant-rich follicular fluid, leaving them more susceptible to oxidative damage [100-102]. They may also be exposed to high oxygen concentrations in incubators and during handling throughout the IVF process, with higher concentrations of oxygen being associated with more ROS, and a positive effect of melatonin being more marked in oocytes exposed to higher oxygen tensions [103]. This oxidative stress modifies the quality of oocytes and embryos, decreasing the fertilisation rate and the success of the infertility treatment [104-106].

Investigators have found an inverse relationship between follicular fluid levels of ROS and success of ART, and these differences do not seem to be related to the cause of infertility. Bedaiwy et al. sequentially analysed the follicular fluid from 138 patients undergoing intracytoplasmic sperm injection ICSI [107]. They found that cycles that resulted in pregnancy were associated with a significantly higher total antioxidant capacity (a measure of the summative effect of antioxidants in the serum [108]) and significantly lower level of ROS [107] but the sample sizes were relatively small. This evidence suggests that intra-follicular oxidative stress may have a significant impact on IVF success rates.

While reactive oxygen species are required for sperm capacitation events $[109,110]$, an imbalance of ROS has been implicated as a factor in reducing the quality and function of sperm [111], with most protection from these effects being afforded by the enzymatic antioxidant, superoxide dismutase [112-116].

One reason for the increased susceptibility of sperm to oxidative stress is the abundance of oxidative targets such as polyunsaturated fatty acids in the plasma membrane of sperm required for fusion with the oocyte and fertilisation [117]. Furthermore, it has been found that DNA fragmentation resulting from both in-vivo and invitro oxidative stress is a major contributor to poor sperm quality and function, and that antioxidative therapies may hold promise in attenuating these effects [118]. As might be expected, such DNA damage has been shown to have a negative impact on fertilisation, blastocyst development [119], and miscarriage rates and pregnancy outcome [120].

The recognition of the association between exposure of gametes and embryos to oxidative stress and a reduction in the success rates of IVF has led investigators to assess whether these adverse effects can either be prevented or reversed, with emphasis being placed on the adjuvant use of oxygen scavengers including melatonin.

The role of melatonin in assisted reproductive technology Oxidative stress occurs at many levels during the treatment of infertility. Interventional studies have begun recently, with an emphasis on oral supplementation of melatonin during the ovarian stimulation phase of the IVF cycle and its effects on gamete and embryo quality. Clinical studies assessing the use of melatonin in IVF are 
summarised in Table 1 and discussed in more detail below.

\section{Effects of melatonin on oocyte quality}

Melatonin is an effective mitigator of mitochondrial DNA damage [121], likely as a result of an increase in electron transport efficiency within mitochondria, thus preventing the formation of ROS [122]. In some situations melatonin may be even more effective at performing this function than specific mitochondrial antioxidants [123], and this particular characteristic may have relevance to its use in the treatment of infertility and the improvement of oocyte quality and maturity.

Oocyte quality begins to deteriorate immediately following ovulation, a process thought to be inflammatory [124] and through its production of cytokines and proteases is associated with an increase in ROS which can inhibit oocyte maturation $[13,125,126]$. A very recent murine study found that oxidative stress in oocytes may begin as early as 8 hours after ovulation, rising exponentially thereafter. This study also found that in-vitro addition of $1 \mathrm{mM}$ of melatonin to oocyte culture media significantly ameliorated these time-dependent effects, resulting in $54 \%$ of fertilise oocytes reaching the blastocyst stage in the presence of melatonin compared with $29 \%$ in the controls [127]. This study not only showed that an imbalance of ROS is an important cause of impaired oocyte quality in-vitro, but also that the addition of melatonin could reverse these effects.

The follicular environment is naturally protective against oxidative damage to the oocyte [128]. To illustrate this, Tamura et al. sampled follicular fluid at oocyte retrieval and measured intrafollicular concentrations of melatonin and the oxidative stress marker, 8-hydroxy2 '-deoxyguanosine (8-OHdG). Melatonin concentrations were directly proportional to follicular growth and, as expected, inversely correlated with 8-OHdG levels.

Kang et al. [129] investigated in-vitro porcine oocyte media supplemented with and without melatonin. They found a significantly lower level of ROS and a greater proportion of MII (mature) oocytes in the melatonin group but without an increase in cleavage frequency or blastocyst cell number. Tamura et al. [125] incubated mouse germinal vesicles exposed to $\mathrm{H}_{2} \mathrm{O}_{2}$ with several different concentrations of melatonin. After 12 hours, a positive dose-response relationship was found between increasing amounts of melatonin and the number of mature oocytes. These results strongly suggest that melatonin supplementation in-vitro is associated with a reduction in oxidative stress and improved oocyte maturation.

The literature is conflicting, however, with other animal studies finding an optimal melatonin range of $10^{-6}$ to $10^{-9} \mathrm{M}$ in in-vitro maturation media, with both higher and lower doses having negative effects $[130,131]$.
These findings are in agreement with human studies which have demonstrated that lower concentrations of melatonin in culture media improved nuclear maturation rate of immature MI oocytes [132], implantation rate and an insignificant increase in clinical pregnancy rate [133] with an optimal threshold of $10^{-5} \mathrm{M}$ to $10^{-9} \mathrm{M}$. Both studies agreed that higher concentrations worsened outcomes. Although there is significant evidence to support a role for melatonin in oocyte maturation in-vitro, further investigation is warranted to confirm the optimal effective dose.

A recent review concluded that oral administration of melatonin reduces intrafollicular oxidative damage and increases fertilisation rates [36]. Unfortunately, most studies addressing the use of melatonin in infertility treatment have been conducted with patients as their own controls ('before and after' comparison) [36,125,134]. In the absence of proper control or placebo groups, it must be assumed that any beneficial effects thus observed are explained by the phenomenon of regression toward the mean $[135,136]$.

Other human studies have been promising, but unfortunately, have also been challenged by design limitations. Eryilmaz et al. [137] performed an unblinded randomise controlled trial assessing melatonin supplementation in women with sleep disturbances undergoing IVF. The investigators randomise 30 patients to receive $3 \mathrm{mg}$ nocte of oral melatonin from day 3-5 of their cycle up until administration of the human chorionic gonadotrophin (HCG) trigger. Controls received no additional treatment. They found a significantly increased number of oocytes, increased number of metaphase II oocytes and increased percentage of Grade 1 embryos $(69.3 \%$ vs $44.8 \%, \mathrm{p}<0.05)$. The authors did not mention controlling or accounting for concurrent adjuvant treatments, nor did they account for the number of previous failed IVF cycles. In addition, their patients had a mean duration of infertility of 6-7 years and the aetiology of infertility was not considered.

Despite its limitations, these findings were in keeping with another larger unblinded randomised trial looking specifically at the effect of melatonin on IVF outcomes. Eighty women were randomised to receiving melatonin $3 \mathrm{mg} /$ day or no treatment from the commencement of $\mathrm{GnRH}$ agonist administration. The percentage of mature oocytes was higher in the melatonin group $(p<0.05)$ as was the proportion of high quality embryos, however, an increase in clinical pregnancy rate did not reach statistical significance [138]. Additionally, patients with cancelled cycles were not included in the analysis making these findings susceptible to attrition bias.

One drawback of the studies already discussed is the lack of a placebo control. Others have overcome the challenge of recruiting patients for a placebo-controlled 
Table 1 Summary of human studies assessing the use of melatonin in IVF

\begin{tabular}{lllll}
\hline Study Design & $\begin{array}{l}\text { NICE } \\
\text { Level of } \\
\text { evidence }\end{array}$ & $\begin{array}{l}\text { Sample Intervention } \\
\text { size }\end{array}$ & Control Outcomes \\
\hline
\end{tabular}

\section{Melatonin alone}

\begin{tabular}{|c|c|c|c|c|c|}
\hline $\begin{array}{l}\text { Tamura } \\
\text { et al. } 2012 \\
\text { [36] }\end{array}$ & $\begin{array}{l}\text { Uncontrolled } \\
\text { before - after } \\
\text { study }\end{array}$ & $2^{-}$ & 9 & $\begin{array}{l}3 \text { mg melatonin po from } \\
\text { day } 5 \text { of menstrual cycle } \\
\text { to oocyte collection } \\
(n=9)\end{array}$ & $\begin{array}{l}\text { Previous cycle without } \\
\text { melatonin }(n=9)\end{array}$ \\
\hline $\begin{array}{l}\text { Tamura } \\
\text { et al. } 2008 \\
{[125]}\end{array}$ & $\begin{array}{l}\text { Prospective } \\
\text { cohort }\end{array}$ & $2^{+}$ & 115 & $\begin{array}{l}3 \text { mg melatonin po from } \\
\text { day } 5 \text { to oocyte } \\
\text { collection }(n=56)\end{array}$ & No melatonin $(n=59)$ \\
\hline $\begin{array}{l}\text { Tamura } \\
\text { et al. } 2008 \\
{[125]}\end{array}$ & $\begin{array}{l}\text { Uncontrolled } \\
\text { before - after } \\
\text { study }\end{array}$ & $2^{-}$ & 112 & $\begin{array}{l}3 \text { mg melatonin po from } \\
\text { day } 5 \text { to oocyte } \\
\text { collection }(n=56)\end{array}$ & $\begin{array}{l}\text { Previous cycle without } \\
\text { melatonin }(n=56)\end{array}$ \\
\hline $\begin{array}{l}\text { Eryilmaz } \\
\text { et al. } 2011 \\
{[137]}\end{array}$ & $\begin{array}{l}\text { Unblinded } \\
\text { randomised } \\
\text { controlled trial }\end{array}$ & $1^{-}$ & 60 & $\begin{array}{l}3 \text { mg melatonin po from } \\
\text { day } 3-5 \text { until HCG } \\
\text { injection }(n=30)\end{array}$ & No melatonin $(n=30)$ \\
\hline
\end{tabular}

$\begin{array}{lll}\begin{array}{l}\text { Batioglu } \\ \text { et al. 2012 }\end{array} & \begin{array}{l}\text { Single-blinded } \\ \text { randomised } \\ \text { [138] }\end{array} & \begin{array}{l}\text { controlled trial } \\ \text { (only } \\ \text { embryologists } \\ \text { were blinded) }\end{array} \\ & \\ & \\ \text { Nishihara } & \begin{array}{l}\text { Uncontrolled } \\ \text { before - 2fter }\end{array} \\ \text { et al. 2014 } & \begin{array}{l}\text { befor } \\ \text { [134] }\end{array} & \text { study }\end{array}$

$3 \mathrm{mg}$ melatonin po No melatonin $(n=45)$

$(n=40)$

7

$3 \mathrm{mg}$ melatonin po for at least 2 weeks leading up to $\mathrm{HCG}$ trigger in second cycle $(n=97)$ $(n=97)$
Higher rate of good embryos in melatonin cycle (65\% vs $27 \%)^{*}$

No difference in fertilisation or clinical pregnancy rate

Higher fertilisation rate in melatonin cycle (50\% vs 20.2\%)

No difference in pregnancy rate

Higher number of oocytes in melatonin group (11.5 vs 6.9)*

Higher MII oocyte counts (9 vs 4.4)*

Higher G1 embryo transfer rate (69.3 vs 44.8)*

No differences in fertilisation, implantation or clinical pregnancy rates

Higher percentage of MII oocytes in melatonin group (81.9\% vs $75.8 \%)^{*}$

Higher number of $\mathrm{G} 1$ embryos $(3.2 \text { vs } 2.5)^{*}$

No difference in number of oocytes, fertilisation rate or clinical pregnancy rate

No melatonin in first cycle Higher ICSI fertilisation rate in melatonin group (77.5\% vs $69.3 \%)^{*}$

Higher rate of good quality embryos (Day 3) $(65.6 \%$ vs 48.0\%)*

No difference in maturation rate, blastocyst rate or good quality blastocysts (Day 5)

\section{Combinations with melatonin}

Rizzo et al. Unblinded 12010 [139] randomised controlled trial
65

3 mg melatonin daily +2 g myo-inositol po bd $+200 \mathrm{mcg}$ folic acid po bd from day of $\mathrm{GnRH}$ administration $(n=32)$

\begin{tabular}{|c|c|}
\hline $\begin{array}{l}\text { Unfer et al. } \\
2011 \text { [165] }\end{array}$ & $\begin{array}{l}\text { Uncontrolled } \\
\text { before - after } \\
\text { study }\end{array}$ \\
\hline
\end{tabular}

2 g myo-inositol po +200 mcg folic acid po in the morning and $3 \mathrm{mg}$ melatonin po $+2 \mathrm{~g}$ myoinositol po +200mcg folic acid po in the evening for 3 months leading to second cycle of IVF
Pacchiarotti Double- $\quad 1^{+} \quad 388$

et al. 2013 blinded

[164] randomised controlled trial
$2 \mathrm{~g}$ myo-inositol po bd $+200 \mathrm{mcg}$ folic acid pc from day of $\mathrm{GnRH}$ administration $(n=33)$
Higher number of MII oocytes in melatonin group (6.56 vs 5.76$)^{*}$ Lower number of immature oocytes (1.31 in vs 1.90)*

No difference in fertilisation rate, embryos transferred, implantation rate or clinical pregnancy rate

No trial medication in first Higher number of $\mathrm{Ml}$ and Mll oocytes in cycle treatment cycle (3.11 vs 2.35)*

Higher number of G1 or G2 embryos transferred (0.35 vs 0.13$)^{*}$

Clinical pregnancy rate $19.6 \%$ in treatment cycle

No differences in number of oocytes or fertilisation rate

4 g myo-inositol $+400 \mathrm{mcg}$ folic acid po $(n=180)$

Higher percentage of mature oocytes in melatonin group (48.2\% vs $35.0 \%)^{*}$
+400 mcg folic acid po $(n=178)$ Higher percentage of G1 embryos $(45.7 \% \text { vs } 30.4 \%)^{*}$ 
trial by using adjuvant combinations as a control group. A prospective non-placebo controlled trial comparing myo-inositol (an insulin sensitizing agent) and folate supplementation to myo-inositol, folate and melatonin found that those in the melatonin group achieved a greater number of mature oocytes, fewer immature oocytes and a greater number of top-quality embryos [139]. While this suggests an independent effect of melatonin, it may be that melatonin acts synergistically with these agents, given that melatonin can enhance the effect of other antioxidants (Figure 1). Indeed, other investigators have shown that myo-inositol may also be a useful treatment for infertility in polycystic ovarian syndrome (PCOS), with improvements observed in the quantity of mature oocytes, the number of top quality embryos and the clinical pregnancy rates [140].

\section{Effects of melatonin on sperm quality}

It appears that the reproductive effects of melatonin do not extend only to the female counterpart, with melatonin receptors being demonstrated on spermatozoa [141]. In general, it is accepted that a higher percentage of motile sperm is associated with improved fertilisation rates and Ortiz et al. has shown that the addition of melatonin to seminal samples can improve the overall motility and the percentage of progressively motile spermatozoa [142,143]. Melatonin also appears to inhibit apoptosis in spermatozoa, with a reduction in early apoptotic events being demonstrated in human sperm thus prolonging sperm survival [144]. These effects would serve to improve sperm quality, therefore increasing the probability of successful fertilisation.

Melatonin, through its neutralisation of reactive oxygen and nitrogen species, has been shown in both animal and human studies to improve seminal quality in-vitro. A study investigating the addition of melatonin to semen extender in cryopreserved seminal samples from Holstein bulls resulted in amelioration of the oxidative effects of the freeze-thaw process [145]. Studies in rats also have shown that melatonin has a positive effect on sperm that have been subjected to oxidative stress, improving sperm number, viability and motility [146-148]. Similar results have been found in a small human study in which in-vitro melatonin-treated samples showed a higher percentage of sperm motility and a lower proportion of non-viable spermatozoa [149]. These authors suggested that the mechanism behind their findings was the result of melatonin neutralising reactive nitrogen species [149].

\section{Effects of melatonin on embryo culture media}

Following retrieval, the micro-environment that gametes and embryos are cultured in is an essential determinant of subsequent fertilisation and implantation success. Many investigators have studied the impact of melatonin supplementation of in-vitro culture media in porcine, murine and bovine embryo development, overall demonstrating a beneficial effect [150-152].

Bovine studies have found a higher cleavage rate, increased 8-cell embryo yield and an increased number of blastocysts and blastocyst hatching in embryos cultured with melatonin concentrations ranging between $10^{-5}$ and $10^{-11} \mathrm{M}$ [153-156]. Like supplementation of oocyte culture media, it appears that higher concentrations of melatonin in embryo culture media can be harmful [157].

Therefore, it appears that in-vitro supplementation of embryo culture media with melatonin has a significant impact on the development and quality of embryos, with lower concentrations being more beneficial (and less harmful) than higher ones.

\section{Effects of melatonin on luteal function}

Progesterone is an essential hormone in the development of a receptive endometrium and for support of early pregnancy, and without it, pregnancy will fail. In a normal menstrual cycle, this progesterone is provided by the corpus luteum, which develops when the granulosa cells in the ruptured follicle luteinise. A certain level of ROS are required for normal ovulation (follicular rupture) and corpus luteal function. An imbalance of ROS results in oxidative stress and this has been identified as a potential cause of luteal phase defect $[158,159]$.

Studies have also sought to identify the role of melatonin administration during the luteal phase in patients undergoing IVF. A prospective study of 25 women with luteal phase defect compared 14 women who were given $3 \mathrm{mg} / \mathrm{d}$ of melatonin from the time of their HCG trigger throughout the luteal phase with 11 women who were given no supplements. The findings showed that melatonin supplementation significantly increased progesterone levels $(11.0 \mathrm{ng} / \mathrm{ml}$ vs $8.9 \mathrm{ng} / \mathrm{ml}, \mathrm{p}<0.05)$ [160]. Another study found that melatonin can increase serum progesterone levels in women with a luteal phase defect, but this study did not have a control arm and the observed differences in serum concentrations $(<10 \mathrm{ng} / \mathrm{ml})$ were not clinically significant, making the relevance of these findings questionable [161]. Consequently, the application of melatonin for luteal phase support is yet to be confirmed.

\section{Effects of melatonin on pregnancy rates - human studies}

Several trials designed to determine the efficacy of melatonin in improving pregnancy rates have considered it in combination with folic acid and myo-inositol, a B complex vitamin synthesized endogenously from glucose [139,162-164].

Rizzo et al. [139] in a prospective trial of 65 women compared myo-inositol and folate supplementation to myo-inositol, folate and melatonin. They found a trend 
towards a higher clinical pregnancy rate in the melatonin group, but this did not reach statistical significance.

In a larger double blind randomised controlled trial addressing these agents in PCOS patients undergoing ICSI, Pacchiarotti et al. [164] allocated 178 patients to triple therapy (myo-inositol $4 \mathrm{~g}$, folic acid $400 \mathrm{mcg}$ and melatonin $3 \mathrm{mg}$ per day) and 180 patients to myoinositol and folic acid alone [164]. With this larger sample size, they found higher numbers of mature oocytes ( $48 \%$ vs $35 \%, \mathrm{p}=0.008$ ) and grade 1 embryos ( $45.7 \%$ vs $30.4 \%, \mathrm{p}=0.0045$ ) in patients treated with triple therapy, supporting the role of melatonin in the treatment of infertility caused by PCOS. This does not necessarily demonstrate an independent effect of melatonin on embryo quality or oocyte maturity, and as discussed previously, may represent a synergistic effect with myo-inositol and folic acid, although this has not been proven.

Overall, only a limited number of clinical studies have investigated the use of melatonin to improve pregnancy outcomes in infertile women. These studies have generally been poorly designed, have often compared combination regimens, have investigated a narrow range of melatonin doses and have been unable to conclusively identify an independent positive role for melatonin on clinical pregnancy rates after IVF. There clearly is a need for a large randomised double blind placebo-controlled trial to investigate whether oral melatonin increases clinical pregnancy rates in IVF patients and which dose provides maximal benefit.

Tamura et al. [125] investigated the role of melatonin supplementation in 115 patients who failed to become pregnant in a previous cycle of IVF/ET, with a fertilisation rate of less than or equal to $50 \%$. They used a dose of $3 \mathrm{mg} /$ day in the next IVF cycle from day 5 of the menstrual cycle until oocyte retrieval. The fertilisation rate was significantly higher in the melatonin group when compared with their first cycle $(50.0 \pm 38.0 \%$ vs $22.8 \pm 19.0 \%$, $\mathrm{p}<0.01)$. In addition, intrafollicular melatonin concentrations were significantly increased and the oxidative stress marker 8-OHdG was significantly decreased by melatonin treatment [125]. Furthermore, the pregnancy rate trended towards an improvement in the melatonin group, albeit not reaching statistical significance.

Another prospective longitudinal cohort study addressed the effects on myo-inositol and melatonin supplementation in women who failed to conceive in previous IVF cycles because of poor oocyte quality [165]. Forty six women were treated with myo-inositol $4 \mathrm{~g}$ /day and melatonin $3 \mathrm{mg} /$ day for three months and then underwent another IVF cycle. After this treatment, there were statistically significant improvements in the number of mature oocytes and fertilisation rate. The number of top-quality embryos transferred was also higher than the previous cycle. The clinical pregnancy rate after supplementation was $19.6 \%$. Because this was a before-after study and patients were only included if they failed to conceive in their first cycle, it is difficult to comment on the significance of this clinical pregnancy rate as an appropriate control group was not used.

Unfortunately, both studies were of low quality using a before and after comparison with regression to the mean likely explaining observed differences [136].

\section{Systematic reviews and meta-analyses}

Only one meta-analysis has been performed specifically assessing the use of melatonin in IVF. This recent systematic review and meta-analysis of five randomise controlled trials found a pooled risk ratio of 1.21 (95\% CI 0.98 - 1.50) in favour of melatonin for the outcome of clinical pregnancy rate. However, the authors suggested that the adequacy of the data evaluating the usefulness of melatonin is poor, and that it should not yet be recommended for routine use [166]. While they did not find any worsening of the outcomes of IVF, the authors commented on the lack of live birth rate as an outcome measure as well as the imprecision encountered in all studies considered [166].

On the other hand, melatonin is also known to be remarkably safe, with the Cochrane systematic review and meta-analysis finding no association between antioxidant supplementation and adverse effects for women involved in treatment [88]. This meta-analysis which considered studies of melatonin as well as other antioxidants, found a similar non-statistically significant improvement in clinical pregnancy rate when using any antioxidant (OR $1.30,95 \%$ CI $0.92-1.85)$ with a total sample size of over 2000 patients [88].

\section{Conclusion and future directions}

While the beneficial nature of melatonin, an endogenous anti-oxidant, has been known for decades, the investigation into the role of melatonin in the treatment of infertility is still in its infancy. Good quality evidence has emerged from other disciplines indicating the utility of melatonin in the treatment of a variety of medical conditions. For example, a recent phase II double blind placebo controlled randomised trial has shown that melatonin can help reduce chronic pelvic pain in women with endometriosis potentially through its effects on brain-derived neurotrophic factor and beneficial effects on sleep quality [57]. Level II evidence has also determined the effectiveness of melatonin as an analgesic in temporomandibular disorders [167] and as a method of reducing oxidative stress and improving dyspnoea in patients with chronic obstructive pulmonary disease [6]. Despite this, melatonin use in infertility treatment still lacks adequate evidence to recommend routine use. 
Infertility treatments are associated with significant levels of reactive oxygen species which have the potential to negatively affect the quality of oocytes and embryos. Melatonin shows promise as an adjunctive therapy in the treatment of infertility. Its unique anti-oxidative characteristics and safety profile make it an ideal potential adjuvant therapy to be further investigated in well designed double blind randomised placebo-controlled trials.

\section{Abbreviations}

IVF: In-vitro fertilisation; ART: Assisted reproductive technology; ICSI: Intracytoplasmic sperm injection; ET: Embryo transfer; ROS: Reactive oxygen species; DNA: Deoxyribonucleic acid; GnRH: Gonadotrophin releasing hormone; 8-OHdG: 8-hydroxy- 2'-deoxyguanosine; MI: Meiosis I; MII: Meiosis II; PCOS: Polycystic ovarian syndrome; HCG: Human chorionic gonadotrophin; LH: Luteinising hormone.

\section{Competing interests}

The authors declare that they have no competing interests.

\section{Authors' contributions}

SF and LR had significant roles in drafting, revising and authorising this paper for publication. Both authors read and approved the final manuscript.

\section{Authors' information}

SF (MBBS(hon) BMedSc(hon)) is an Obstetrics and Gynaecology Senior Registrar at Monash Health in Melbourne, Australia. He is also a Clinical Research Fellow and Adjunct Lecturer in the Department of Obstetrics and Gynaecology at Monash University in Melbourne, Australia.

LR is Associate Professor in the Department of Obstetrics and Gynaecology at Monash University and Head of Reproductive Medicine at Monash Medical Centre. He is the Research Director of Monash IVF and a Board Member of the World Endometriosis Society, the World Endometriosis Research Foundation and the Fertility Society of Australia. He also serves on the Grants and Scholarship Committee of the Royal Australian and New Zealand College of Obstetricians and Gynaecologists.

\section{Author details}

'MIMR-PHI Institute of Medical Research, 246 Clayton Rd, Clayton 3168, Victoria, Australia. ${ }^{2}$ Monash University, Department of Obstetrics and Gynaecology, Level 5 Monash Medical Centre, 246 Clayton Rd, Clayton 3168, Victoria, Australia. ${ }^{3}$ Monash IVF, 252 Clayton rd, Clayton 3168, Victoria, Australia.

\section{Received: 24 July 2014 Accepted: 11 October 2014}

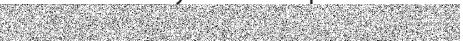

\section{References}

1. Lundsberg L, Pal L, Gariepy A, Xu X, Chu M, Illuzzi J: Knowledge, attitudes, and practices regarding conception and fertility: a population-based survey among reproductive-age United States women (in press). Fertil Steril 2014, 101:767.

2. Chakravarty S, Rizvi SI: Physiological effects of melatonin: implications on human health. Biomedicine 2008, 28:252-255.

3. Madalinski M: Does a melatonin supplement alter the course of gastroesophageal reflux disease? World J Gastrointest Pharmacol Ther 2011, 2:50-51.

4. Biran V, Phan Duy A, Decobert F, Bednarek N, Alberti C, Baud O: Is melatonin ready to be used in preterm infants as a neuroprotectant? Dev Med Child Neurol 2014, 56:717-723.

5. Bai J, Dong L, Song Z, Ge H, Cai X, Wang G, Liu P: The role of melatonin as an antioxidant in human lens epithelial cells. Free Radic Res 2013, 47:635-642

6. de Matos $C A$, de Bruin $P$, de Bruin V, Nunes D, Pereira E, Cavalcante M Andrade $\mathrm{G}$ : Melatonin reduces lung oxidative stress in patients with chronic obstructive pulmonary disease: a randomise, double-blind, placebo-controlled study. J Pineal Res 2012, 53:238-244.

7. Scheuer C, Pommergaard H, Rosenberg J, Gögenur I: Melatonin's protective effect against UV radiation: a systematic review of clinical and experimental studies [Epub ahead of print]. Photodermatol Photoimmunol Photomed 2013, 30:180.
8. Russcher M, Koch B, Nagtegaal E, van der Putten K, ter Wee P, Gaillard C: The role of melatonin treatment in chronic kidney disease. Front Biosci (Landmark Ed) 2012, 1:2644-2656

9. Carbajo-Pescador S, Ordoñez R, Benet M, Jover R, García-Palomo A, Mauriz J, González-Gallego J: Inhibition of VEGF expression through blockade of Hif1a and STAT3 signalling mediates the anti-angiogenic effect of melatonin in HepG2 liver cancer cells. Br J Cancer 2013, 109:83-91.

10. Nawrot-Porabka K, Jaworek J, Leja-Szpak A, Szklarczyk J, Konturek S, Reiter R: Luminal melatonin stimulates pancreatic enzyme secretion via activation of serotonin-dependent nerves. Pharmacol Rep 2013, 65:494-504

11. Csaba G: The pineal regulation of the immune system: 40 years since the discovery. Acta Microbiol Immunol Hung 2013, 60:77-91.

12. Acuña-Castroviejo D, Escames G, Venegas C, Díaz-Casado M, Lima-Cabello E, López L, Rosales-Corral S, DX T, Reiter R: Extrapineal melatonin: sources, regulation, and potential functions [Epub ahead of print]. Cell Mol Life Sci 2014, 71:2997.

13. Reiter R, Rosales-Corral S, Manchester L, Tan D: Peripheral reproductive organ health and melatonin: ready for prime time. Int J Mol Sci 2013, 14:7231-7272.

14. Hsing A, Meyer T, Niwa S, Quraishi S, Chu L: Measuring serum melatonin in epidemiologic studies. Cancer Epidemiol Biomarkers Prev 2010, 19:932-937.

15. Waldhauser F, Waldhauser M, Lieberman $H$, Deng M, Lynch $H$, Wurtmann R: Bioavailability of oral melatonin in humans. Neuroendocrinology 1984, 39:307-313.

16. Li C, Li G, Tan D, Li F, Ma X: A novel enzyme-dependent melatonin metabolite in humans. J Pineal Res 2013, 54:100-106.

17. Shreeve N, Cagampang F, Sadek K, Tolhurst M, Houldey A, Hill C, Brook N, Macklon N, Cheong Y: Poor sleep in PCOS; is melatonin the culprit? Hum Reprod 2013, 28:1348-1353.

18. de Almeida E, Di Mascio P, Harumi T, Spence D, Moscovitch A, Hardeland R, Cardinali D, Brown G, Pandi-Perumal S: Measurement of melatonin in body fluids: standards, protocols and procedures. Childs Nerv Syst 2011, 27:879-891.

19. Reiter R, Tan D, Tamura H, Cruz M, Fuentes-Broto L: Clinical relevance of melatonin in ovarian and placental physiology: a review. Gynecol Endocrinol 2014, 30:83-89.

20. Zhu Y, Fu A, Hoffman A, Figueiro M, Carskadon M, Sharkey K, Rea M: Advanced sleep schedules affect circadian gene expression in young adults with delayed sleep schedules. Sleep Med 2013, 14:449-455.

21. Wilhelmsen-Langeland A, Saxvig I, Pallesen S, Nordhus I, Vedaa O, Lundervold A, Bjorvatn B: A randomise controlled trial with bright light and melatonin for the treatment of delayed sleep phase disorder: effects on subjective and objective sleepiness and cognitive function. J Biol Rhythms 2013, 28:306-321.

22. Cortesi F, Giannotti F, Sebastiani T, Panunzi S, Valente D: Controlled-release melatonin, singly and combined with cognitive behavioural therapy, for persistent insomnia in children with autism spectrum disorders: a randomise placebo-controlled trial. J Sleep Res 2012, 21:700-709.

23. Yadav $S, H a l d a r ~ C:$ Reciprocal interaction between melatonin receptors (Mel(1a), Mel(1b), and Mel(1c)) and androgen receptor (AR) expression in immunoregulation of a seasonally breeding bird, Perdicula asiatica: role of photoperiod. J Photochem Photobiol B 2013, 5:52-60.

24. Clarke I, Caraty A: Kisspeptin and seasonality of reproduction. Adv Exp Med Biol 2013, 784:411-430

25. Abecia J, Forcada F, González-Bulnes A: Pharmaceutical control of reproduction in sheep and goats. Vet Clin North Am Food Anim Pract 2011, 27:67-79.

26. Zaidi J, Jurkovic D, Campbell S, Okokon E, Tan S: Circadian variation in uterine artery blood flow indices during the follicular phase of the menstrual cycle. Ultrasound Obstet Gynecol 1995, 5:406-410.

27. Silman R: Melatonin: a contraceptive for the nineties. Eur J Obstet Gynecol Reprod Biol 1993, 49:3-9.

28. Kojo S: Vitamin C: basic metabolism and its function as an index of oxidative stress. Curr Med Chem 2004, 11:1041-1064.

29. Bouayed J, Bohn T: Exogenous antioxidants - double-edged swords in cellular redox state: health beneficial effects at physiologic doses versus deleterious effects at high doses. Oxid Med Cell Longev 2010, 3:228-237.

30. Valko M, Leibfritz D, Moncol J, Cronin M, Mazur M, Telser J: Free radicals and antioxidants in normal physiological functions and human disease. Int J Biochem Cell Biol 2007, 39:44-84.

31. Rahman K: Studies on free radicals, antioxidants, and co-factors. Clin Interv Aging 2007, 2:219-236. 
32. Wood S, Quinn A, Troupe S, Kingsland C, Lewis-Jones I: Seasonal variation in assisted conception cycles and the influence of photoperiodism on outcome in in-vitro fertilisation cycles. Hum Fertil 2006, 9:223-229.

33. Agarwal A, Gupta S, Sharma RK: Role of oxidative stress in female reproduction. Reprod Biol Endocrinol 2005, 3. http://www.rbej.com/content/3/1/28.

34. Srinivasan V, Spence W, Pandi-Perumal SR, Zakharia R, Bhatnagar K, Brzezinski A: Melatonin and human reproduction: shedding light on the darkness hormone. Gynecol Endocrinol 2009, 25:779-785.

35. Dubocovich M, Markowska M: Functional MT1 and MT2 melatonin receptors in mammals. Endocrine 2005, 27:101-110.

36. Tamura H, Takasaki A, Taketani T, Tanabe M, Kizuka F, Lee L, Tamura I, Maekawa R, Aasada $\mathrm{H}$, Yamagata $Y$, Sugino $\mathrm{N}$ : The role of melatonin as an antioxidant in the follicle. J Ovarian Res 2012, 5. http://www.ovarianresearch.com/content/5/1/5.

37. Tan D, Manchester L, Reiter R, Qi W, Karbownik M, Calvo J: Significance of melatonin in antioxidative defense system: reactions and products. Biol Signals Recept 2000, 9:137-159.

38. Acuña-Castroviejo D, Reiter R, Menéndez-Peláez A, Pablos M, Burgos A Characterization of high-affinity melatonin binding sites in purified cell nuclei of rat liver. J Pineal Res 1994, 16:100-112.

39. Benítez-King G, Huerto-Delgadillo L, Antón-Tay F: Binding of 3H-melatonin to calmodulin. Life Sci 1993, 53:201-207.

40. Ressmeyer A, Mayo J, Zelosko V, Sáinz R, Tan D, Poeggeler B, Antolín I, Zsizsik B, Reiter R, Hardeland R: Antioxidant properties of the melatonin metabolite N1-acetyl-5-methoxykynuramine (AMK): scavenging of free radicals and prevention of protein destruction. Redox Rep 2003, 8:205-213.

41. Galano A, Tan D, Reiter R: On the free radical scavenging activities of melatonin's metabolites, AFMK and AMK. J Pineal Res 2013, 54:245-257.

42. Tan D, Reiter R, Manchester L, Yan M, El-Sawi M, Sainz R, Mayo J, Kohen R, Allegra M, Hardeland R: Chemical and physical properties and potential mechanisms: melatonin as a broad spectrum antioxidant and free radical scavenger. Curr Top Med Chem 2002, 2:181-197.

43. Mayo J, Sainz R, Antoli I, Herrera F, Martin V, Rodriguez C: Melatonin regulation of antioxidant enzyme gene expression. Cell Moll Life Sci 2002, 59:1706-1713.

44. Tamura H, Nakamura Y, Korkmaz A, Manchester L, Tan D, Sugino N, Reiter R: Melatonin and the ovary: physiological and pathophysiological implications. Fertil Steril 2009, 92:328-343.

45. Urata Y, Honma S, Goto S, Todoroki S, lida T, Cho S, Honma K, Kondo T: Melatonin induces gamma-glutamylcysteine synthetase mediated by activator protein-1 in human vascular endothelial cells. Free Radic Biol Med 1999, 27:838-847.

46. Hardeland R: Melatonin metabolism in the central nervous system. Curr Neuropharmacol 2010, 8:168-181.

47. Watson R: Melatonin in the Promotion of Health 2nd edition. United States: CRC Press; 2011

48. Sanchez-Barcelo EJ, Mediavilla MD, Tan DX, Reiter RJ: Clinical uses of melatonin: evaluation of human trials. Curr Med Chem 2010, 17:2070-2095.

49. Kolli V, Kanakasabapathy I, Faith M, Ramamoorthy H, Isaac B, Natarajan K, Abraham P: A preclinical study on the protective effect of melatonin against methotrexate-induced small intestinal damage: effect mediated by attenuation of nitrosative stress, protein tyrosine nitration, and PARP activation. Cancer Chemother Pharmacol 2013, 71:1209-1218.

50. Zasada K, Karbownik-Lewinska M: Comparison of potential protective effects of melatonin and propylthiouracil against lipid peroxidation caused by nitrobenzene in the thyroid gland [Epub ahead of print]. Toxicol Ind Health 2013.

51. Tomov B, Popov D, Tomova R, Vladov N, Den Otter W, Krastev Z: Therapeutic response of untreatable hepatocellular carcinoma after application of the immune modulators IL-2, BCG and melatonin. Anticancer Res 2013, 33:4531-4535.

52. Kim J, Lee Y, Kim B, Kim S, Kim D, Jo K, Lee S, Lee K, Baik H: Melatonin improves inflammatory cytokine profiles in lung inflammation associated with sleep deprivation. Mol Med Rep 2012, 5:1281-1284.

53. Siah K, Wong R, Ho K: Melatonin for the treatment of irritable bowel syndrome. World J Gastroenterol 2014, 20:2492-2498.

54. Jena G, Trivedi P: A review of the use of melatonin in ulcerative colitis: experimental evidence and new approaches. Inflamm Bowel Dis 2014, 20:553-563.

55. Trivedi P, Jena G: Melatonin reduces ulcerative colitis-associated local and systemic damage in mice: investigation on possible mechanisms. Dig Dis Sci 2013, 58:3460.
56. Chojnacki C, Wiśniewska-Jarosińska M, Kulig G, Majsterek I, Reiter R, Chojnacki J: Evaluation of enterochromaffin cells and melatonin secretion exponents in ulcerative colitis. World J Gastroenterol 2013, 19:3602-3607.

57. Schwertner A, Conceição dos Santos C, Costa G, Deitos A, de Souza A, de Souza I, Torres I, da Cunha Filho J, Caumo W: Efficacy of melatonin in the treatment of endometriosis: a phase II, randomise, double-blind, placebo-controlled trial. Pain 2013, 154:874-881.

58. Turi A, Garzetti GG: The pattern of melatonin in amenorrheic women affected by sterility. Acta Eur Fertil 1993, 24:71-74.

59. Tang P, Chan T, Tang G, Pang S: Plasma melatonin profile and hormonal interactions in the menstrual cycles of anovulatory infertile women treated with gonadotropins. Gynecol Obstet Invest 1998, 45:247-252.

60. Webley GE, Hearn JP: Local production of progesterone by the corpus luteum of the marmoset monkey in response to perfusion with chorionic gonadotrophin and melatonin in-vivo. J Endocrinol 1987 112:449-457.

61. Attarchi M, Darkhi H, Khodarahmian M, Dolati M, Kashanian M, Ghaffari M, Mirzamohammadi E, Mohammadi S: Characteristics of menstrual cycle in shift workers. Glob J Health Sci 2013, 5:163-172.

62. Grajewski B, Nguyen MM, Whelan EA, Cole RJ, Hein MJ: Measuring and identifying large-study metrics for circadian rhythm disruption in female flight attendants. Scand J Work Environ Health 2003, 29:337-346.

63. Lawson CC, Whelan EA, Lividoti Hibert EN, Spiegelman D, Schernhammer ES, Rich-Edwards JW: Rotating shift work and menstrual cycle characteristics. Epidemiology 2011, 22:305-312.

64. Miyauchi F, Nanjo K, Otsuka K: Effects of night shift on plasma concentrations of melatonin, $\mathrm{LH}, \mathrm{FSH}$ and prolactin, and menstrual irregularity. Sangyo lgaku 1992, 34:545-550.

65. Boczek-Leszczyk $E_{1}$ Juszczak M: The influence of melatonin on human reproduction. Pol Merkur Lekarski 2007, 23:128-130.

66. Voordouw B, Euser R, Verdonk R, Alberda B, de Jong F, Drogendijk A, Fauser $B$, Cohen M: Melatonin and melatonin-progestin combinations alter pituitary-ovarian function in women and can inhibit ovulation. J Clin Endocrinol Metab 1992, 74:108-117.

67. Salhab M, Dhorne-Pollet S, Auclair S, Guyader-Joly C, Brisard D, Dalbies-Tran R, Dupont J, Ponsart C, Mermillod P, Uzbekova S: In-vitro maturation of oocytes alters gene expression and signaling pathways in bovine cumulus cells. Mol Reprod Dev 2013, 80:166-182.

68. Itoh M, Ishizuka B, Kuribayashi Y, Amemiya A, Sumi Y: Melatonin, its precursors, and synthesizing enzyme activities in the human ovary. Mol Hum Reprod 1999, 5:402-408.

69. Wurtman R, Axelrod J, Potter L: The uptake of h3-melatonin in endocrine and nervous tissues and the effects of constant light exposure. J Pharmacol Exp Ther 1964, 143:314-318.

70. Brzezinski A, Seibel M, Lynch H, Deng M, Wurtman R: Melatonin in human preovulatory follicular fluid. J Clin Endocrinol Metab 1987, 64:865-867.

71. Rönnberg L, Kauppila A, Leppäluoto J, Martikainen H, Vakkuri O: Circadian and seasonal variation in human preovulatory follicular fluid melatonin concentration. J Clin Endocrinol Metab 1990, 71:492-496.

72. Nakamura $\mathrm{Y}$, Tamura H, Takayama H, Kato H: Increased endogenous level of melatonin in preovulatory human follicles does not directly influence progesterone production. Fertil Steril 2003, 80:1012-1016.

73. Carlomagno G, Nordio M, Chiu TT, Unfer V: Contribution of myo-inositol and melatonin to human reproduction. Eur J Obstet Gynecol Reprod Biol 2011, 159:267-272

74. Hobson S, Lim R, Gardiner E, Alers N, Wallace E: Phase I pilot clinical trial of antenatal maternally administered melatonin to decrease the level of oxidative stress in human pregnancies affected by pre-eclampsia (PAMPR): study protocol. BMJ Open 2013, 3. http://bmjopen.bmj.com/ content/3/9/e003788.long.

75. Tamura H, Nakamura Y, Pilar Terron M, Flores L, Manchester L, Tan D, Sugino N, Reiter R: Melatonin and pregnancy in the human. Reprod Toxicol 2008, 25:291-303.

76. Lemley C, Camacho L, Vonnahme K: Uterine infusion of melatonin or melatonin receptor antagonist alters ovine feto-placental hemodynamics during midgestation. Biol Reprod 2013, in press.

77. Wong C, Jow G, Kaizaki A, Fan L, Tien L: Melatonin ameliorates brain injury induced by systemic lipopolysaccharide in neonatal rats. Neuroscience 2014, 267:147-156

78. Miller SL, Yawno T, Alers NO, Castillo-Melendez M, Supramaniam VG, VanZyl N, Sabaretnam T, Loose JM, Drummond GR, Walker DW, Jenkin G, Wallace 
EM: Antenatal antioxidant treatment with melatonin to decrease newborn neurodevelopmental deficits and brain injury caused by fetal growth restriction. J Pineal Res 2014, 56(3):283-94.

79. Sack R, Lewy A, Erb D, Vollmer W, Singer C: Human melatonin production decreases with age. J Pineal Res 1986, 3:379-388.

80. Toffol E, Kalleinen N, Haukka J, Vakkuri O, Partonen T, Polo-Kantola P. Melatonin in perimenopausal and postmenopausal women: associations with mood, sleep, climacteric symptoms, and quality of life. Menopause 2014, 21:493-500.

81. Bellipanni G, DI Marzo F, Blasi F, Di Marzo A: Effects of melatonin in perimenopausal and menopausal women: our personal experience. Ann N Y Acad Sci 2005, 1057:393-402.

82. Maria S, Witt-Enderby PA: Melatonin effects on bone: potential use for the prevention and treatment for osteopenia, osteoporosis, and periodontal disease and for use in bone-grafting procedures. J Pineal Res 2013.

83. Kotlarczyk MP, Lassila HC, O'Neil CK, D'Amico F, Enderby LT, Witt-Enderby PA, Balk JL: Melatonin osteoporosis prevention study (MOPS): a randomise, double-blind, placebo-controlled study examining the effects of melatonin on bone health and quality of life in perimenopausal women. $J$ Pineal Res 2012, 52:414-426.

84. Meliska CJ, Martinez LF, Lopez AM, Sorenson DL, Nowakowski S, Parry BL: Relationship of morningness-eveningness questionnaire score to melatonin and sleep timing, body mass index and atypical depressive symptoms in peri- and post-menopausal women. Psychiatry Res 2011, 188:88-95.

85. Barron ML: Light exposure, melatonin secretion, and menstrual cycle parameters: an integrative review. Biol Res Nurs 2007, 9:49-69.

86. Hemadi M, Shokri S, Pourmatroud E, Moramezi F, Khodadai A: Follicular dynamic and immunoreactions of the vitrified ovarian graft after host treatment with variable regimens of melatonin. Am J Reprod Immunol 2012, 67:401-412.

87. Jahnke G, Marr M, Myers C, Wilson R, Travlos G, Price C: Maternal and developmental toxicity evaluation of melatonin administered orally to pregnant Sprague-Dawley rats. Toxicol Sci 1999, 50:271-279.

88. Showell M, Brown J, Clarke J, Hart R: Antioxidants for female subfertility. Cochrane Database Syst Rev 2013.

89. Kucuktulu E: Protective effect of melatonin against radiation induced nephrotoxicity in rats. Asian Pac J Cancer Prev 2012, 13:4101-4105.

90. Staikou C, Kyrozis A, Moschovos C, Fassoulaki A: Effects of morning melatonin administration on electroencephalographic theta to alpha power ratio in reproductive versus postmenopausal healthy female volunteers. Neurosci Lett 2012, 507:90-93.

91. Weaver D: Reproductive safety of melatonin: a "wonder drug" to wonder about. J Biol Rhythms 1997, 12:682.

92. Gill A: Poisons Standard 2013, Standard for the Uniform Scheduling of Medicines and Poisons No. 4 (SUSMP 4), Australian Government Department of Health and Ageing. In Book Poisons Standard 2013, Standard for the Uniform Scheduling of Medicines and Poisons No. 4 (SUSMP 4). City: Australian Government Department of Health and Ageing; 2013.

93. Maestroni GJ, Cardinali DP, Esquifino Al, Pandi-Perumal SR: Does melatonin play a disease-promoting role in rheumatoid arthritis? J Neuroimmunol 2005, 158:106-111.

94. Hong YG, Riegler JL: Is melatonin associated with the development of autoimmune hepatitis? J Clin Gastroenterol 1997, 25:376-378.

95. Fourman LT, Robert Meyer B: Autoimmune hepatitis in association with ramelteon. J Clin Gastroenterol 2013, 47:651-654.

96. Constantinescu CS: Melanin, melatonin, melanocyte-stimulating hormone, and the susceptibility to autoimmune demyelination: a rationale for light therapy in multiple sclerosis. Med Hypotheses 1995, 45:455-458.

97. Sulli A, Maestroni GJ, Villaggio B, Hertens E, Craviotto C, Pizzorni C, Briata M, Seriolo B, Cutolo M: Melatonin serum levels in rheumatoid arthritis. Ann N Y Acad Sci 2002, 966:276-283.

98. Guerin P, El Mouatassim S, Menezo Y: Oxidative stress and protection against reactive oxygen species in the pre-implantation embryo and its surroundings. Hum Reprod Update 2001, 7:175-189.

99. Palini S, Benedetti S, Tagliamonte MC, De Stefani S, Primiterra M, Polli V, Rocchi P, Catalani S, Battistelli S, Canestrari F, Bulletti C: Influence of ovarian stimulation for IVF/ICSI on the antioxidant defence system and relationship to outcome. Reprod Biomed Online 2014, 29:65.

100. Yoshida M, Ishigati K, Nagai T, Chikyu M, Pursel V: Glutathione concentration during maturation and after fertilisation in pig ooctes: relevance to the ability of oocytes to form male pronucleus. Biol Reprod 1993, 49:89-94.
101. Fatehi A, Roelen B, Colenbrander B, Schoevers E, Gadella B, Beverst M, van den Hurk R: Presence of cumulus cells during in-vitro fertilisation protects the bovine oocyte against oxidative stress and improves first cleavage but does not affect further development. Zygote 2005, 13:177-185.

102. Huang B, Li Z, Ai J, Zhu L, Li Y, Jin L, Zhang H: Antioxidant capacity of follicular fluid from patients undergoing in-vitro fertilisation. Int J Clin Exp Pathol 2014, 7:2273-2282.

103. Papis K, Poleszczuk O, Wenta-Muchalska E, Modlinski J: Melatonin effect on bovine embryo development in-vitro in relation to oxygen concentration. J Pineal Res 2007, 43:321-326.

104. Takahashi T, Takahashi E, Igarashi H, Tezuka N, Kurachi H: Impact of oxidative stress in aged mouse oocytes on calcium oscillations at fertilisation. Mol Reprod Dev 2003, 66:143-152

105. du Plessis S, Makker K, Desai N, Agarwal A: Impact of oxidative stress on IVF. Expert Rev Obstet Gynecol 2008, 3:539-554

106. Combelles C, Gupta S, Agarwal A: Could oxidative stress influence the invitro maturation of oocytes? Reprod Biomed Online 2009, 18:864-880.

107. Bedaiwy M, Elnashar S, Goldberg J, Sharma R, Mascha E, Arrigain S, Agarwal A, Falcone T: Effect of follicular fluid oxidative stress parameters on intracytoplasmic sperm injection outcome. Gynecol Endocrinol 2012, 28:51-55.

108. Ghiselli A, Serafini M, Natella F, Scaccini C: Total antioxidant capacity as a tool to assess redox status: critical view and experimental data. Free Radic Biol Med 2000, 29:1106-1114.

109. O'Flaherty C, de Lamirande E, Gagnon C: Positive role of reactive oxygen species in mammalian sperm capacitation: triggering and modulation of phosphorylation events. Free Radic Biol Med 2006, 41:528-540.

110. Donà G, Fiore C, Tibaldi E, Frezzato F, Andrisani A, Ambrosini G, Fiorentin D, Armanini D, Bordin L, Clari G: Endogenous reactive oxygen species content and modulation of tyrosine phosphorylation during sperm capacitation. Int J Androl 2011, 34:411.

111. Donà G, Fiore C, Andrisani A, Ambrosini G, Brunati A, Ragazzi E, Armanini D, Bordin L, Clari G: Evaluation of correct endogenous reactive oxygen species content for human sperm capacitation and involvement of the NADPH oxidase system. Hum Reprod 2011, 26:3264-3273.

112. Aitken $\mathrm{R}$, Clarkson J: Cellular basis of defective sperm function and its association with the genesis of reactive oxygen species by human spermatozoa. J Reprod Fertil 1987, 81:459-469.

113. Alvarez J, Touchstone J, Blasco L, Storey B: Spontaneous lipid peroxidation and production of hydrogen peroxide and superoxide in human spermatozoa. superoxide dismutase as major enzyme protectant against oxygen toxicity. J Androl 1987, 8:338-348.

114. Guz J, Gackowski D, Foksinski M, Rozalski R, Zarakowska E, Siomek A, Szpila A, Kotzbach M, Kotzbach R, Olinski R: Comparison of oxidative stress/DNA damage in semen and blood of fertile and infertile men. PLOS One 2013, 8. e68490.

115. Jones R, Mann T, Sherins R: Peroxidative breakdown of phospholipids in human spermatozoa, spermicidal properties of fatty acid peroxides, and protective action of seminal plasma. Fertil Steril 1979, 31:531-537.

116. Koppers A, Mitchell L, Wang P, Lin M, Aitken R: Phosphoinositide 3-kinase signalling pathway involvement in a trunctated apoptotic cascade associated with motility loss and oxidative DNA damage in human spermatozoa. Biochem J 2011, 2011:687-698.

117. Aitken R, De luliis G: On the possible origins of DNA damage in human spermatozoa. Mol Hum Reprod 2010, 16:3-13.

118. Wright C, Milne S, Leeson H: Sperm DNA damage caused by oxidative stress: modifiable clinical, lifestyle and nutritional factors in male infertility. Reprod Biomed Online 2014, 28:684-703.

119. Seli E, Gardner D, Schoolcraft W, Moffatt O, Sakkas D: Extent of nuclear DNA damage in ejaculated spermatozoa impacts on blastocyst development after in-vitro fertilisation. Fertil Steril 2004, 82:378-383.

120. Lewis S, Aitken R: DNA damage to spermatozoa has impacts on fertilisation and pregnancy. Cell Tissue Res 2005, 322:33-41.

121. El-Raey M, Geshi M, Somfai T, Kaneda M, Hirako M, Abdel-Ghaffar A, Sosa G, El-Roos M, Nagai T: Evidence of melatonin synthesis in the cumulus oocyte complexes and its role in enhancing oocyte maturation in-vitro in cattle. Mol Reprod Dev 2011, 78:250-262.

122. Hardeland R: Antioxidative protection by melatonin: multiplicity of mechanisms from radical detoxification to radical avoidance. Endocrine 2005, 27:119-130

123. Lowes D, Webster N, Murphy M, Galley H: Antioxidants that protect mitochondria reduce interleukin- 6 and oxidative stress, improve 
mitochondrial function, and reduce biochemical markers of organ dysfunction in a rat model of acute sepsis. Br J Anaesth 2013, 110:472-480.

124. Espey L: Current status of the hypothesis that mammalian ovulation is comparable to an inflammatory reaction. Biol Reprod 1994, 50:233-238.

125. Tamura H, Takasaki A, Miwa I, Taniguchi K, Maekawa R, Asada H, Taketani T, Matsuoka A, Yamagata Y, Shimamura K, Morioka H, Ishikawa H, Reiter RJ, Sugino N: Oxidative stress impairs oocyte quality and melatonin protects oocytes from free radical damage and improves fertilisation rate. J Pineal Res 2008, 44(3):280-87.

126. Tamura H, Taketani T, Takasaki A, Sugino N: Influence of oxidative stress on oocyte quality and protective role of melatonin as an antioxidant. In Book Influence of oxidative stress on oocyte quality and protective role of melatonin as an antioxidant. 7th edition. Munich, Germany: Journal fur Reproduktionsmedizin und Endokrinologie; 2010:366.

127. Lord T: Melatonin prevents postovulatory oocyte aging in the mouse and extends the window for optimal fertilisation in-vitro. Biol Reprod 2013, 88:67

128. Knapen M, Zusterzeel P, Peters W, Steegers E: Glutathione and glutathione-related enzymes in reproduction: a review. Eur J Obstet Gynecol Reprod Biol 1999, 82:171-184.

129. Kang J, Koo O, Kwon D, Park H, Jang G, Kang S, Lee B: Effects of melatonin on in-vitro maturation of porcine oocyte and expression of melatonin receptor RNA in cumulus and granulosa cells. J Pineal Res 2009, 46:22-28.

130. Salimi M, Salehi M, Masteri Farahani R, Dehghani M, Abadi M, Novin M, Nourozian M, Hosseini A: The effect of melatonin on maturation, glutathione level and expression of HMGB1 gene in Brilliant Cresyl Blue (BCB) stained immature oocyte. Cell J 2014, 15:294-301.

131. Bahadori MH, Ghasemian F, Ramezani M, Asgari Z: Melatonin effect during different maturation stages of oocyte and subsequent embryo development in mice. Iran J Reprod Med 2013, 11:11-18.

132. Wei D, Zhang C, Xie J, Song X, Yin B, Liu Q, Hu L, Hao H, Geng J, Wang P: Supplementation with low concentrations of melatonin improves nuclear maturation of human oocytes in-vitro. J Assist Reprod Genet 2013, 30:933-938.

133. Kim M, Park E, Kim H, Choi W, Cho J, Lee W, Cha K, Kim Y, Lee D, Yoon T: Does supplementation of in-vitro culture medium with melatonin improve IVF outcome in PCOS? Reprod Biomed Online 2013, 26:22-29.

134. Nishihara T, Hashimoto S, Ito K, Nakaoka Y, Matsumoto K, Hosoi Y, Morimoto Y: Oral melatonin supplementation improves oocyte and embryo quality in women undergoing in-vitro fertilisation-embryo transfer. Gynecol Endocrinol 2014, 30:359-362.

135. Barnett AG, van der Pols JC, Dobson AJ: Regression to the mean: what it is and how to deal with it. Int J Epidemiol 2005, 34:215-220.

136. Rombauts $L$ : Is there a recommended maximum starting dose of FSH in IVF? J Assist Reprod Genet 2007, 24:343-349.

137. Eryilmaz O, Devran A, Sarikaya E, Aksakal F, Mollamahmutoğlu L, Cicek N: Melatonin improves the oocyte and the embryo in IVF patients with sleep disturbances, but does not improve the sleeping problems. J Assist Reprod Genet 2011, 28:815-820.

138. Batıoğlu A, Şahin U, Gürlek B, Öztürk N, Ünsal E: The efficacy of melatonin administration on oocyte quality. Gynecol Endocrinol 2012, 28:91-93.

139. Rizzo P, Raffone E, Benedetto V: Effect of the treatment with myo-inositol plus folic acid plus melatonin in comparison with a treatment with myo-inositol plus folic acid on oocyte quality and pregnancy outcome in IVF cycles. a prospective, clinical trial. Embase European Rev Med Pharmacol Sci 2010, 14:555-561.

140. Unfer V, Carlomagno G, Rizzo P, Raffone E, Roseff S: Myo-inositol rather than D-chiro-inositol is able to improve oocyte quality in intracytoplasmic sperm injection cycles. a prospective, controlled, randomise trial. Eur Rev Med Pharmacol Sci 2011, 15:452-457.

141. Konakchieva R: Physiological role of melatonin in human reproductive system - Signaling, targets and receptor localization. In Book Physiological role of melatonin in human reproductive system - Signaling, targets and receptor localization. Bulgaria: 2012.

142. Ortiz A, Espino J, Bejarano I, Lozano G, Monllor F, García J, Pariente J, Rodríguez A: High endogenous melatonin concentrations enhance sperm quality and short-term in-vitro exposure to melatonin improves aspects of sperm motility. J Pineal Res 2011, 50:132-139.

143. Espino J, Ortiz A, Bejarano I, Lozano G, Monllor F, Garcia J, Rodriguez A, Pariente J: Melatonin protects human spermatozoa from apoptosis via melatonin receptor- and extracellular signal-regulated kinase-mediated pathways. Fertil Steril 2011, 95:2290-2296.

144. Espino J, Bejarano I, Ortiz A, Lozano G, García J, Pariente J, Rodríguez A Melatonin as a potential tool against oxidative damage and apoptosis in ejaculated human spermatozoa. Fertil Steril 2010, 94:1915-1917.

145. Ashrafi I, Kohram H, Ardabili F: Antioxidative effects of melatonin on kinetics, microscopic and oxidative parameters of cryopreserved bull spermatozoa. Anim Reprod Sci 2013, 139:25-30.

146. Nasiraei-Moghadam S, Parivar K, Ahmadiani A, Movahhedin M, Vaez Mahdavi M: Protective effect of melatonin against inequality-induced damages on testicular tissue and sperm parameters. Int J Fertil Steril 2014, 7:313-322.

147. Kim S, Lee I, Baek H, Shin I, Moon C, Kim S, Yun W, Nam K, Kim H, Kim J: Melatonin prevents gentamicin-induced testicular toxicity and oxidative stress in rats [EPub ahead of print]. Andrologia 2013, 46:1032.

148. Liu C, Gao P, Xu S, Wang Y, Chen C, He M, Yu Z, Zhang L, Zhou Z: Mobile phone radiation induces mode-dependent DNA damage in a mouse spermatocyte-derived cell line: a protective role of melatonin. Int J Radiat Biol 2013, 89:993-1001.

149. du Plessis S, Hagenaar K, Lampiao F: The in-vitro effects of melatonin on human sperm function and its scavenging activities on NO and ROS. Andrologia 2010, 42:112-116.

150. Rodriguez-Osorio N, Kim I, Wang H, Kaya A, Memili E: Melatonin increases cleavage rate of porcine preimplantation embryos in-vitro. J Pineal Res 2007, 43:283-288.

151. Ishizuka B, Kuribayashi Y, Murai K, Amemiya A, Itoh M: The effect of melatonin on in-vitro fertilisation and embryo development in mice. J Pineal Res 2000, 28:48-51.

152. Choi J, Park SM, Lee E, Kim JH, Jeong YI, Lee JY, Park SW, Kim HS, Hossein MS, Jeong YW, Kim S, Hyun SH, Hwang WS: Anti-apoptotic effect of melatonin on preimplantation development of porcine parthenogenetic embryos. Mol Reprod Dev 2008, 75(7):1127-35.

153. Asgari Z, Ghasemian F, Ramezani M, Bahadori MH: The effect of melatonin on the developmental potential and implantation rate of mouse embryos. Cell J 2012, 14:203-208

154. Mehaisen GM, Saeed AM: In-vitro development rate of preimplantation rabbit embryos cultured with different levels of melatonin. Zygote 2013, 28:1-5.

155. Wang F, Tian X, Zhang L, Gao C, He C, Fu Y, Ji P, Li Y, Li N, Liu G: Beneficial effects of melatonin on in-vitro bovine embryonic development are mediated by melatonin receptor 1. J Pineal Res 2014, 56:333-342.

156. Wang F, Tian X, Zhou Y, Tan D, Zhu S, Dai Y, Liu G: Melatonin improves the quality of in-vitro produced (IVP) bovine embryos: implications for blastocyst development, cryotolerance, and modifications of relevant gene expression. PLoS One 2014, 9:e93641.

157. Succu S, Pasciu V, Manca ME, Chelucci S, Torres-Rovira L, Leoni GG, Zinellu A, Carru C, Naitana S, Berlinguer F: Dose-dependent effect of melatonin on postwarming development of vitrified ovine embryos. Theriogenology 2014, 81:1058-1066.

158. Sugino N, Takiguchi S, Kashida S, Takayama H, Yamagata Y, Nakamura Y, Kato $\mathrm{H}$ : Suppression of intracellular superoxide dismutase activity by antisense oligonucleotides causes inhibition of progesterone production by rat luteal cells. Biol Reprod 1999, 61:1133-1138.

159. Scarpellini F, Mastrone M, Sbracia M, Scarpellini L: Serum lipoperoxide level variations in normal and luteal phase defect cycles. Gynecol Obstet Invest 1996, 42:28-30.

160. Taketani T, Tamura H, Takasaki A, Lee L, Kizuka F, Tamura I, Taniguchi K, Maekawa R, Asada H, Shimamura K, Reiter RJ, Sugino N: Protective role of melatonin in progesterone production by human luteal cells. J Pineal Res 2011, 51(2):207-13.

161. Takasaki A, Tamura H, Taniguchi K, Asada H, Taketani T, Matsuoka A, Yamagata $\mathrm{Y}$, Shimamura K, Morioka $\mathrm{H}$, Sugino $\mathrm{N}$ : Luteal blood flow and luteal function. J Ovarian Res 2009, 2. http://www.ovarianresearch.com/ content/2/1/1

162. Ciotta L, Stracquadanio M, Pagano I, Carbonaro A, Palumbo M, Gulino F: Effects of myo-inositol supplementation on oocyte's quality in PCOS patients: a double blind trial. Eur Rev Med Pharmacol Sci 2011, 15:509-514.

163. Nazzaro A, Salerno A, Marino S, Granato C, Pastore E: The addiction of melatonin to myo-inositol plus folic acid improve oocyte quality and pregnancy outcome in IVF cycle. a prospective clinical trial. Hum Reprod 2011, 26:1227. 
164. Pacchiarotti A, Carlomagno G, Unfer V, Frati P, Pacchiarotti A, Prapas N: Role of Myo-inositol and melatonin supplementation in follicular fluid of IVF patients with polycystic ovarian syndrome: a randomise controlled trial. ClinicalTrialsgov 2013. http://clinicaltrials.gov/show/NCT01540747.

165. Unfer V, Raffone E, Rizzo P, Buffo S: Effect of a supplementation with myoinositol plus melatonin on oocyte quality in women who failed to conceive in previous in-vitro fertilisation cycles for poor oocyte quality: a prospective, longitudinal, cohort study. Gynaecol Endocrinol 2011, 27:857-861.

166. Seko L, Moroni R, Leitao V, Teixeira D, Nastri C, Martins W: Melatonin supplementation during controlled ovarian stimulation for women undergoing assisted reproductive technology: systematic review and metaanalysis of randomise controlled trials. Fertil Steril 2014, 101:154-161.

167. Vidor LP, Torres IL, de Souza IC C, Fregni F, Caumo W: Analgesic and sedative effects of melatonin in temporomandibular disorders: a doubleblind, randomise, parallel-group, placebo-controlled study. J Pain symptom Manage 2013, 46:422-432

doi:10.1186/s13048-014-0098-y

Cite this article as: Fernando and Rombauts: Melatonin: shedding light on infertility? - a review of the recent literature. Journal of Ovarian Research 2014 7:98.

\section{Submit your next manuscript to BioMed Central and take full advantage of:}

- Convenient online submission

- Thorough peer review

- No space constraints or color figure charges

- Immediate publication on acceptance

- Inclusion in PubMed, CAS, Scopus and Google Scholar

- Research which is freely available for redistribution 